See Article page 118 in the December 2020 issue.

\section{Commentary: A new little piece for a great puzzle}

\author{
Valentina Mancini, MD, ${ }^{\mathrm{a}}$ Aziz Omar, $\mathrm{MD},{ }^{\mathrm{a}}$ and \\ Michele Di Mauro, MD, PhD, MSc ${ }^{\mathrm{b}, \mathrm{c}}$
}

Recent decades have seen an increasing number of aortic valve replacements (AVRs) performed each year, with a significant shift from mechanical prosthesis to bioprosthesis implantation owing to the reluctance of even younger patients to take oral anticoagulants. ${ }^{1}$ Both European and American guidelines have supported bioprosthesis implantation in patients age $>60$ years. ${ }^{2}$ However, with the average lifespan of a bioptosthesis, estimated at 15 years in elderly patients but less in younger patients, we should expect a significant increase in patients with structural degeneration and failure of aortic valve bioprostheses. ${ }^{1-3}$

Redo surgical operation carries a high risk, especially in patients with a patent previous coronary bypass associated with a degenerated AVR and serious comorbidities. ${ }^{4}$ Transcatheter aortic valve-in-valve (ViV) implantation in a failed bioprosthesis appears to be an increasingly good option with extensive worldwide experience. ${ }^{5}$

Moreover, with the advent of transcatheter aortic valve replacement (TAVR), the number of patients needing a further AVR is expected to increase; thus, it makes sense to evaluate the transcatheter ViV approach for a degenerated TAVR, as in the case reported by Ricciardi and colleagues. After careful evaluation with the heart team, the authors chose the transapical route for TAVR.

From the ${ }^{\mathrm{a} D e p a r t m e n t}$ of Clinical Sciences and Bioimaging, Università degli Studi G d'Annunzio, Chieti-Pescara, Italy; ${ }^{\mathrm{b}}$ Cardiothoracic Surgery Department, Heart \& Vascular Center, Maastricht University Medical Center, Maastricht, The

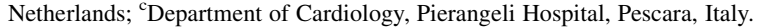

Disclosures: The authors reported no conflicts of interest.

The Journal policy requires editors and reviewers to disclose conflicts of interest and to decline handling or reviewing manuscripts for which they may have a conflict of interest. The editors and reviewers of this article have no conflicts of interest.

Received for publication Oct 24, 2020; revisions received Oct 24, 2020; accepted for publication Oct 28, 2020; available ahead of print Nov 18, 2020.

Address for reprints: Michele Di Mauro, MD, PhD, MSc, Cardiothoracic Surgery Unit, Heart and Vascular Centre, Maastricht University Medical Centre, Cardiovascular Research Institute Maastricht, P Debyelaan 25, 6202 AZ Maastricht, The Netherlands (E-mail: mdimauro1973@gmail.com).

JTCVS Techniques 2021;5:20

2666-2507

Copyright $(2020$ The Authors. Published by Elsevier Inc. on behalf of The American Association for Thoracic Surgery. This is an open access article under the CC BY-NCND license (http://creativecommons.org/licenses/by-nc-nd/4.0/).

https://doi.org/10.1016/j.xjtc.2020.10.045

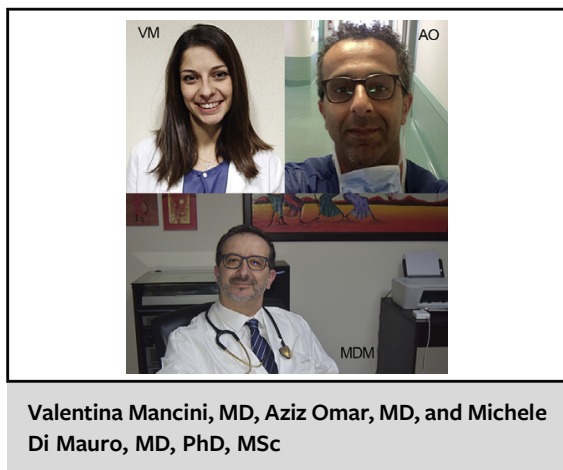

CENTRAL MESSAGE

No route for ViV should be ineludibly foreclosed in high-risk redo cases; in this case report, the authors had success with a transapical approach.

Recently published long-term results of the VIVID Registry ${ }^{6}$ reported a rate of reintervention for TAVR degeneration at 8 years of $93.5 \% ; 16$ of 40 patients $(40 \%)$ needing a redo received a new TAVR. The Edwards balloonexpandable valve, as used in this case, was associated with a high risk of new intervention (hazard ratio [HR], $3.34 ; P=.02$ ). Interestingly, among 1006 patients undergoing aortic VIV, a transapical route was used in roughly $25 \%$, although non-transfemoral access was identified as an independent risk factor $(\mathrm{HR}, 1.43)$ for lower survival. However, as noted by the authors, ${ }^{7}$ little is known about the results of transapical ViV for TAVR degeneration, and this interesting case report adds a new piece to the great puzzle of ViV.

\section{References}

1. Head SJ, Çelik M, Kappetein AP. Mechanical versus bioprosthetic aortic valve replacement. Eur Heart J. 2017;38:2183-91.

2. Singh M, Sporn ZA, Schaff HV, Pellikka PA. ACC/AHA versus ESC guidelines on prosthetic heart valve management: JACC guideline comparison. J Am Coll Cardiol. 2019;73:1707-18.

3. Maganti M, Rao V, Armstrong S, Feindel CM, Scully HE, David TE. Redo valvular surgery in elderly patients. Ann Thorac Surg. 2009;87:521-5.

4. Kirsch M, Nakashima K, Kubota S, Houël R, Hillion ML, Loisance D. The risk of reoperative heart valve procedures in octogenarian patients. J Heart Valve Dis. 2004;13:991-6.

5. Smith CR, Leon MB, Mack MJ, Miller DC, Moses JW, Svensson LG, et al; PARTNER trial investigators. Transcatheter versus surgical aortic-valve replacement in high-risk patients. N Engl J Med. 2011;364:2187-98.

6. Bleiziffer S, Simonato M, Webb JG, Rodés-Cabau J, Pibarot P, Kornowski R, et al. Long-term outcomes after transcatheter aortic valve implantation in failed bioprosthetic valves. Eur Heart J. 2020;41:2731-42.

7. Ricciardi G, Cavallotti L, Alamanni F, Roberto M. Reoperative transapical transcatheter aortic valve implantation for a degenerated biological valve. J Thorac Cardiovasc Surg Tech. 2020;4:118-20. 